\title{
Pulse oximetry in bronchiolitis: is it needed?
}

This article was published in the following Dove Press journal:

Therapeutics and Clinical Risk Management

12 October 2015

Number of times this article has been viewed

\author{
Mohamed A Hendaus ${ }^{1,2}$ \\ Fatima A Jomha ${ }^{3}$ \\ Ahmed H Alhammadi ${ }^{1,2}$ \\ 'Department of Pediatrics, General \\ Pediatrics Division, Hamad \\ Medical Corporation, \\ ${ }^{2}$ Weill-Cornell Medical College, \\ Doha, Qatar; ${ }^{3}$ School of Pharmacy, \\ Lebanese International University, \\ Khiara, Lebanon
}

\begin{abstract}
Infants admitted to health-care centers with acute bronchiolitis are frequently monitored with a pulse oximeter, a noninvasive method commonly used for measuring oxygen saturation. The decision to hospitalize children with bronchiolitis has been largely influenced by pulse oximetry, despite its questionable diagnostic value in delineating the severity of the illness. Many health-care providers lack the appropriate clinical fundamentals and limitations of pulse oximetry. This deficiency in knowledge might have been linked to changes in the management of bronchiolitis. The aim of this paper is to provide the current evidence on the role of pulse oximetry in bronchiolitis. We discuss the history, fundamentals of operation, and limitations of the apparatus. A search of the Google Scholar, Embase, Medline, and PubMed databases was carried out for published articles covering the use of pulse oximetry in bronchiolitis.
\end{abstract}

Keywords: bronchiolitis, children, monitor, oxygen

\section{Introduction}

Bronchiolitis is a respiratory condition usually caused by viral lower respiratory tract infection in infants and young children. The pathophysiology of bronchiolitis commences with acute inflammation, followed by edema, and augmentation of mucus production. ${ }^{1}$ Bronchiolitis is the most common cause of infant hospitalization in the USA, costing the health-care system more than $\$ 1$ billion annually. ${ }^{2}$ The American Academy of Pediatrics (AAP) strongly advocates that the history and physical examination form the focus of diagnostic procedures for bronchiolitis so as to produce the correct diagnosis and to evaluate the severity of the illness. ${ }^{1}$

The decision to hospitalize children with bronchiolitis has been largely influenced by pulse oximetry, despite its questionable diagnostic value in delineating the severity of the illness. ${ }^{3}$ Recently, infants admitted to health-care centers with acute bronchiolitis have been frequently monitored with a pulse oximeter, ${ }^{4}$ a noninvasive method commonly used for measuring oxygen saturation. ${ }^{5}$

Many health-care providers lack the appropriate clinical fundamentals and limitations of pulse oximetry. ${ }^{5,6}$ This deficiency in knowledge has been linked to changes in the management of bronchiolitis, ${ }^{5}$ perhaps because many emergency department physicians depend on oximetry when deciding to admit the infant to the hospital. Moreover, their decisions to admit might be based on only a $2 \%$ difference in oxygen saturation. ${ }^{3}$

Despite being considered as a weak prognosticator of respiratory distress, oxygen saturation is very closely linked to the increased rate of hospitalization of infants with acute bronchiolitis ${ }^{7}$ and has been considered a major factor in the length of stay in hospital. ${ }^{8,9}$ There is no consensus regarding the oxygen saturation cutoff value for the initiation of oxygen supplements in infants with bronchiolitis. ${ }^{10,11}$ In a study conducted by on clinical characteristics associated with hospitalization and length of stay, Corneli et $\mathrm{al}^{7}$ showed that among infants admitted with acute bronchiolitis, the unique
Correspondence: Mohamed A Hendaus Department of Pediatrics, General Pediatrics Division, Hamad Medical Corporation, PO Box 3050, Doha, Qatar Tel +97444392 239

Fax +974 4443957 I

Emailmhendaus@yahoo.com
Therapeutics and Clinical Risk Management 2015:I I 1573-1578

1573

Dovepress

http://dx.doi.org//0.2147/TCRM.S93176 (c) (7) (8) 2015 Hendaus et al. This work is published by Dove Medical Press Limited, and licensed under Creative Commons Attribution - Non Commercial (unported, v3.0) License. The full terms of the License are available at http://creativecommons.org/licenses/by-nc/3.0/. Non-commercial uses of the work are permitted without any further permission from Dove Medical Press Limited, provided the work is properly attributed. Permissions beyond the scope of the License are administered by Dove Medical Press Limited. Intormation on
how to request permission may be found at: http://www.dovepress.com/permissions.php 
decision point for a prediction of longer stay was oxygen saturation measurement of $97 \%$ or less at presentation. It has been postulated that if non-ill-appearing infants with mild-to-moderate bronchiolitis can be discharged home from the emergency department, fewer infants will be admitted to the hospital and lower health-care expenses will occur. ${ }^{4}$

Hemoglobin is usually considered functional if it has the capacity to bind and transport oxygen, producing oxyhemoglobin and deoxyhemoglobin. ${ }^{12-14}$ Failure of hemoglobin to bind or transport oxygen results in carboxyhemoglobin $(\mathrm{COHb})$ and methemoglobin. ${ }^{13,14}$

A dangerous pitfall of pulse oximetry is that the presence of $\mathrm{COHb}$ can overestimate arterial oxygenation. This outcome is induced by the specific features of $\mathrm{COHb}$, which displays red-light absorption analogous to that of oxyhemoglobin. The same concept applies to the presence of methemoglobin. ${ }^{6}$

$\mathrm{PaO}_{2}$, by definition, is the partial pressure of oxygen diffused in blood, ${ }^{13}$ while the calculation and measurement of the percentage of oxygen bound to hemoglobin in arterial blood is termed oxygen saturation $\left(\mathrm{SpO}_{2}\right){ }^{12}$

Formerly, $\mathrm{SpO}_{2}$ measurement was obtained solely by drawing blood samples and measuring $\mathrm{O}_{2}$ levels directly. This approach was considered invasive and was inadequate to support real-time measurements. ${ }^{15}$ Pulse oximetry is a noninvasive technique for overseeing a human's $\mathrm{SpO}_{2}$. The most common available device is the transmissive application mode, which uses a sensor device placed on a thin part of the patient's body, such as the fingertip, earlobe, or across the foot. ${ }^{16}$

In this paper, we describe the physiologic principles, common applications, limitations, and clinical studies of pulse oximetry in bronchiolitis.

\section{Methods}

A search of the Google Scholar, Embase, Medline, and PubMed databases was carried out using different combinations of the following terms: pulse, oximetry, infants, children, operation, mode, and limitations. In addition, we searched the references of the identified articles for additional articles. The articles included in this review were restricted to randomized controlled trials, cross-sectional studies, well-designed prospective pilots, and guidelines from well-known international organizations such as the AAP, the Scottish Intercollegiate Guidelines Network (SIGN), and the National Institute for Health and Care Excellence (NICE). We also referred to websites for terminology and definitions. We did not count on case reports, studies funded by device manufacturers,

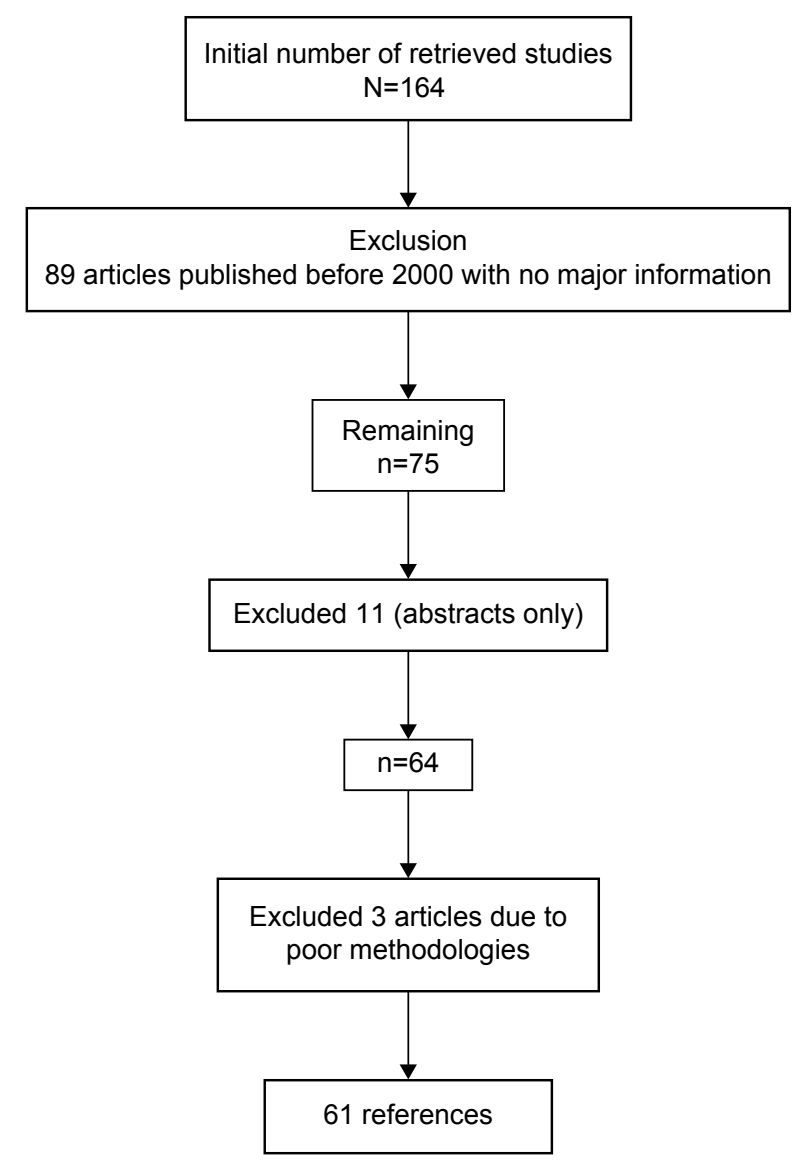

Figure I Flow diagram of selection of references.

and small studies. Finally, the search was limited to studies of disease that were published in English, Portuguese, and Spanish from 1895 until July 2015 (Figure 1).

\section{Results}

\section{History}

In 1935, Karl Matthes refined the first 2-wavelength ear $\mathrm{O}_{2}$ saturation meter with red and green filters, leading to the production of the first apparatus to measure $\mathrm{O}_{2}$ saturation. The evolution of oximetry was boosted during World War II, when an approach was needed to monitor oxygenation in aviators flying in high-pressure cockpits at high altitudes. ${ }^{17}$

In 1964, Robert Shaw put together the first complete reading ear oximeter by using eight wavelengths of light. It was made commercially available by Hewlett-Packard (Palo Alto, CA, USA) in 1970, but its use was limited to cardiac catheterization labs, perhaps due to cost and size. ${ }^{18}$

In 1970, investigations carried out by Takuo Aoyagi and Michio Kishi on dye-dilution techniques for measuring cardiac output resulted in the development of a photoplethysmogram, which produces time-dependent volumetric variations 
in living tissues, resulting in the development of a pulse oximeter. ${ }^{12,18}$

Thirteen years later, in 1983, Bill New introduced the Nellcor Pulse Oximeter (Covidien Corporation, Dublin, Ireland) for inpatient as well as outpatient settings. ${ }^{19}$ Pulse oximetry was of special interest in the neonatal intensive care unit where premature neonates have had a high rate of morbidity and mortality with inadequate oxygenation..$^{20}$ One of the limitations of pulse oximetry was motion artifact, leading to false results. The logic behind the inaccurate results is that during movements, several pulse oximeter devices cannot differentiate between moving venous blood and pulsating arterial blood, resulting in underestimation of $\mathrm{SpO}_{2} \cdot{ }^{21,22}$ These results prompted Masimo and his team to introduce Signal Extraction Technology that can accurately measure $\mathrm{SpO}_{2}$ during low perfusion or when the patient moves, by separating the arterial signal from the venous and other signals. ${ }^{23}$ Pulse oximeters that separate the arterial signal from the venous are now available and have greater sensitivity/specificity than older models. ${ }^{24}$

\section{Principles of operation of pulse oximetry}

A regular pulse oximeter uses an electronic processor and a pair of small light-emitting diodes facing a photodiode through a translucent part of the patient's body, such as the fingertip or an earlobe. Typically, one light-emitting diode is red, with a wavelength of $660 \mathrm{~nm}$, while the other is infrared with a wavelength of $940 \mathrm{~nm}$. The absorption of light at these wavelengths is not similar between blood loaded with oxygen and blood lacking oxygen. Oxygenated hemoglobin permits more red light to cross and absorbs more infrared light. On the other hand, deoxygenated hemoglobin permits more infrared light to pass through and imbibes more red light. ${ }^{18,25}$ With every cardiac beat, there is an increase in arterial blood, which temporarily augments arterial blood volume across the measuring site. This will lead to increased light absorption during the surge, creating "waveform" by the photodetector. The term "pulse oximetry" was derived after the observation of peak blood flow with each heartbeat or pulse. The quantity of transmitted light is then measured. The ratio of the red light to the infrared light (ratio of oxygenated hemoglobin to deoxygenated hemoglobin) is then computed by the processor, producing a $\mathrm{SpO}_{2}$ measurement. ${ }^{25}$

\section{Applications}

Pulse oximetry has become ubiquitous in pediatrics. It is generally found in pediatric wards, emergency departments, and pediatric intensive care units.
In addition, pulse oximetry has been widely used in association with respiratory illnesses, cyanosis, during resuscitations, and as a screening tool in the emergency department. It has also been used in the detection of pulsus paradoxus, estimating perfusion, and for screening infants for congenital heart disease. ${ }^{26-39} \mathrm{In}$ adults, the limited literature has shown that pulse oximetry can be used in patients with pulmonary embolism and chronic diseases. ${ }^{40-43}$

\section{Limitations}

Pulse oximeters have several limitations (Table 1). One of them is caused by inadequate signals, especially in cases of anemia, dark skin, bright external light, intravenous dye, nail polish, and low perfusion. ${ }^{21,25,44,45}$ Additionally, owing to the sigmoidal shape of the oxyhemoglobin dissociation curve, pulse oximetry might not detect hypoxemia in individuals with elevated arterial oxygen tension $\left(\mathrm{PaO}_{2}\right)$ levels. ${ }^{25}$ Another limitation of the pulse oximeter is low reading in cases of venous pulsations such as tricuspid regurgitation, severe right heart failure, and tourniquet or blood pressure cuff above the site of the pulse oximeter. ${ }^{44}$ Furthermore, a pulse oximeter might provide unreliable readings $(80 \%-85 \%$ saturation regardless of actual saturation) in cases such as methemoglobinemia. ${ }^{44}$

\section{Bronchiolitis and pulse oximetry}

The association between oxygen saturation and respiratory distress in young infants with respiratory infections is not well established. ${ }^{44}$ However, it has been established that the effect of oxygen saturation on respiratory drive is inferior to carbon dioxide concentrations in the blood ${ }^{46}$ Moreover, while sleeping, children can have physiologic low oxygen saturation $\left(\mathrm{SpO}_{2}\right)$, especially those living at higher altitudes. ${ }^{47}$

Table I Limitations of a pulse oximeter

\begin{tabular}{ll}
\hline Limitations & Condition(s) \\
\hline Inadequate signal & - Anemia \\
& - Dark skin \\
& - Bright external light \\
& - Nail polish \\
& - Low perfusion \\
False hypoxemia & Elevated arterial oxygen \\
& tension (PaO ${ }_{2}$ ) levels \\
Low reading & Venous pulsations such as \\
& - Tricuspid regurgitation \\
& - Severe right heart failure \\
& Tourniquet or blood pressure cuff \\
& above the site of pulse oximeter \\
& Dyshemoglobin \\
Unreliable readings & Methemoglobin \\
& Carboxyhemoglobin
\end{tabular}


Although a pulse oximeter is a handy device to measure the percentage of oxygen-bound hemoglobin in children, it lacks precision particularly in the $76 \%-90 \%$ range. ${ }^{48}$ Currently, there is no international consensus on the $\mathrm{SpO}_{2}$ levels that are required to admit or discharge the pediatric patient with acute bronchiolitis..$^{10,11,49-51}$ For instance, the NICE and the SIGN recommend giving oxygen supplementation to children with bronchiolitis if their oxygen saturation is persistently $<92 \%{ }^{49,51}$ The AAP, on the other hand, suggests providing oxygen supplements to children with acute bronchiolitis for $\mathrm{SpO}_{2}$ of $<90 \%$. $^{10,11}$

Oxygen saturation measurement has become part of the vital signs in the majority of health-care centers, and it is usually adopted by health-care providers to lead their clinical evaluation of respiratory status and their decisions about safe discharge.${ }^{52}$ In the recent bronchiolitis guidelines, the AAP emphasized the importance of history and physical examination, and otherwise recommend little testing, treatment, or intervention including the use of continuous pulse oximetry. ${ }^{1,53}$

Transient desaturation is a normal variant in healthy infants. A study of 103 preterm infants born at $<1,750 \mathrm{~g}$ and $\leq 34$ weeks postmenstrual age, and 99 healthy term infants showed that episodes of intermittent hypoxemia occurred in three-quarters of preterm and almost two-thirds of term infants. The acute intermittent hypoxemia was defined as a decrease in absolute oxygen saturation that was sustained below $90 \%$ for $\geq 5$ seconds. ${ }^{54}$

In a prospective study to assess the accuracy of pulse oximetry in the saturation range of $65 \%-97 \%$, Ross et al ${ }^{18}$ included 225 mechanically ventilated children with an arterial catheter. For every arterial blood gas sample, $\mathrm{SpO}_{2}$ from pulse oximetry and arterial oxygen saturations from CO-oximetry $\left(\mathrm{SaO}_{2}\right)$ were concurrently gathered if the $\mathrm{SpO}_{2}$ was $\leq 97 \%$. The authors concluded that the accuracy of pulse oximetry varies considerably as a function of the $\mathrm{SpO}_{2}$ range. Saturations obtained by pulse oximetry embellish $\mathrm{SaO}_{2}$ from CO-oximetry in the $\mathrm{SpO}_{2}$ range of $76 \%-90 \%$.

A retrospective study conducted by Schroeder et $\mathrm{al}^{4}$ on the impact of pulse oximetry and oxygen therapy on length of stay in bronchiolitis hospitalizations showed that $26 \%$ of children had delayed discharges from the hospital due to the perception of oxygen requirement based on pulse oximetry readings and not clinical findings.

A randomized, double-blind, parallel-group trial was conducted in Canada from 2008 to 2013 on the effect of pulse oximetry on bronchiolitis hospitalization. The study included 213 healthy infants aged 4 weeks to 1 year with mild-to-moderate bronchiolitis and genuine oxygen saturations of $88 \%$ or higher. The investigators deliberately increased the saturation values by 3 percentage points above the true values in the intervention group. The study concluded that among infants who are brought to the emergency department with mild-to-moderate bronchiolitis, infants with a deliberately augmented pulse oximetry reading were less likely to be admitted within 72 hours or to acquire health center care for more than 6 hours than those with genuine oximetry readings. ${ }^{2}$

Lowering the threshold of acceptable $\mathrm{SpO}_{2}$ at discharge could significantly decrease the length of stay for hospitalized infants with mild or moderate bronchiolitis. Cunningham and McMurray conducted a prospective observational study of two oxygen saturation targets ( $\geq 90 \%$ and $\geq 94 \%$ ) for discharge in bronchiolitis. The study included 68 infants with a median age of 14 weeks. The time required for infants to achieve a stable $\mathrm{SpO}_{2} \geq 90 \%$ was a median of 22 hours (interquartile range: 7-39 hours) sooner than the equivalent for stable $\mathrm{SpO}_{2} \geq 94 \%{ }^{8}$

Perhaps simple interventions might ameliorate the issue. In a recently published paper on using quality improvement to reduce continuous pulse oximetry use in children with wheezing, Schondelmeyer et $\mathrm{a}^{55}$ were able to decrease the median duration on continuous pulse oximetry by $70 \%$. The investigators used simple steps such as education about guidelines and acceptable goals for well-timed discontinuation of continuous pulse oximetry.

In addition to its questionable use in bronchiolitis, repeated alarms from pulse oximetry due to false measurement in an active infant or child might lead to alarm fatigue, ${ }^{56}$ which has been associated with dangerous safety occurrences. ${ }^{57-59}$ The Joint Commission stated in its report published in 2013 that $85 \%-99 \%$ of alarm signals are attributed to technical flaws and do not require clinical intervention. As a result, health-care providers become insensitive or develop tolerance to the sounds, leading to "alarm fatigue". As a consequence, clinicians decrease the volume of the alarm or even turn it off, which can have eventually drastic and dreadful repercussions. ${ }^{60}$

In a 6-month pilot study, Martin et al assessed evidencebased protocols to guide pulse oximetry and oxygen weaning in inpatient children with asthma and bronchiolitis. An interprofessional team from Cook Children's Medical Center in the State of Texas initially identified lack of guidelines and deficiencies in oxygen weaning protocols for respiratory therapists or nurses concerning the use of pulse oximetry in young children hospitalized for asthma or bronchiolitis. The team eventually developed evidence-based pulse oximetry 
and oxygen weaning protocols, and compared the outcomes of small samples $(n=15, n=16)$ of the pilot group with those of children admitted with asthma or bronchiolitis prior to the protocol use.

The study concluded that these protocols decreased length of stay by $50 \%$ and shortened both the duration of oxygen supplementation and pulse oximetry monitoring. ${ }^{61}$

\section{Conclusion}

The introduction of pulse oximetry in clinical practice has permitted a plain and noninvasive mode of measuring arterial oxygen saturation. However, it has certain limitations. Considering the current technological progress, randomized controlled clinical trials on how to integrate pulse oximetry into evidence-based diagnostic and management algorithms in bronchiolitis are required.

\section{Summary and recommendations}

- Intermittent hypoxemia physiologically occurs in threequarters of preterm and almost two-thirds of term infants with bronchiolitis.

- Although a pulse oximeter is a handy device to measure the percentage of oxygen-bound hemoglobin in children, it lacks precision, particularly in the $76 \%-90 \%$ range.

- The diagnostic value of pulse oximetry in assessing the severity of bronchiolitis is questionable; hence history and physical examination is important to delineate the correct diagnosis and to evaluate the severity of the illness.

- Overreliance on pulse oximetry measurements may lead to the overdiagnosis of illness severity and increased bronchiolitis admissions.

- Repeated alarms from pulse oximetry by false measurement in an active infant or child might lead to alarm fatigue, leading to possible dreadful outcomes.

- Pulse oximetry should be used only in patients with unstable respiratory status, and development of specific weaning protocols may limit unnecessary admissions, length of stay, cost, and prevent negative outcomes associated with alarm fatigue.

\section{Disclosure}

The authors report no conflicts of interest in this work.

\section{References}

1. Ralston SL, Lieberthal AS, Meissner HC, et al; American Academy of Pediatrics. Clinical practice guideline: the diagnosis, management, and prevention of bronchiolitis. Pediatrics. 2014;134(5):e1474-e1502. doi:10.1542/peds.2014-2742.

2. Schuh S, Freedman S, Coates A, et al. Effect of oximetry on hospitalization in bronchiolitis: a randomized clinical trial. JAMA. 2014;312(7): 712-718. doi:10.1001/jama.2014.8637.
3. Mallory MD, Shay DK, Garrett J, Bordley WC. Bronchiolitis management preferences and the influence of pulse oximetry and respiratory rate on the decision to admit. Pediatrics. 2003;111(1):e45-e51.

4. Schroeder AR, Marmor AK, Pantell RH, Newman TB. Impact of pulse oximetry and oxygen therapy on length of stay in bronchiolitis hospitalizations. Arch Pediatr Adolesc Med. 2004;158(6):527-530.

5. Fouzas S, Priftis KN, Anthracopoulos MB. Pulse oximetry in pediatric practice. Pediatrics. 2011;128(4):740-752. doi:10.1542/peds.20110271.

6. Elliott M, Tate R, Page K. Do clinicians know how to use pulse oximetry? A literature review and clinical implications. Aust Crit Care. 2006;19(4):139-144.

7. Corneli HM, Zorc JJ, Holubkov R, et al; Bronchiolitis Study Group for the Pediatric Emergency Care Applied Research Network. Bronchiolitis: clinical characteristics associated with hospitalization and length of stay. Pediatr Emerg Care. 2012;28(2):99-103. doi:10.1097/ PEC.0b013e3182440b9b.

8. Cunningham S, McMurray A. Observational study of two oxygen saturation targets for discharge in bronchiolitis. Arch Dis Child. 2012;97(4):361-363. doi:10.1136/adc.2010.205211.

9. Unger S, Cunningham S. Effect of oxygen supplementation on length of stay for infants hospitalized with acute viral bronchiolitis. Pediatrics. 2008;121(3):470-475. doi:10.1542/peds.2007-1135.

10. Zorc JJ, Hall CB. Bronchiolitis: recent evidence on diagnosis and management. Pediatrics. 2010;125(2):342-349. doi:10.1542/peds 2009-2092.

11. American Academy of Pediatrics Subcommittee on Diagnosis and Management of Bronchiolitis. Diagnosis and management of bronchiolitis. Pediatrics. 2006;118(4):1774-1793.

12. Dresher RP, Mendelson Y. Reflectance forehead pulse oximetry: effects of contact pressure during walking. Conf Proc IEEE Eng Med Biol Soc. 2006;1:3529-3532.

13. Pittman RN. Oxygen transport in the microcirculation and its regulation. Microcirculation. 2013;20(2):117-137. doi:10.1111/micc.12017.

14. Thom CS, Dickson CF, Gell DA, Weiss MJ. Hemoglobin variants: biochemical properties and clinical correlates. Cold Spring Harb Perspect Med. 2013;3(3):a011858. doi:10.1101/cshperspect.a011858.

15. Patel S, Park H, Bonato P, Chan L, Rodgers M. A review of wearable sensors and systems with application in rehabilitation. J Neuroeng Rehabil. 2012;9:21. doi:10.1186/1743-0003-9-21.

16. Brand TM, Brand ME, Jay GD. Enamel nail polish does not interfere with pulse oximetry among normoxic volunteers. J Clin Monit Comput. 2002;17(2):93-96.

17. Mechem CC. Pulse oximetry. Available from: http://www.uptodate com/contents/pulse-oximetry. Accessed July 11, 2015.

18. Kamat V. Pulse oximetry. Indian J Anaesth. 2002;46(4):261-268.

19. History of pulse oximetry. Available from: http://www.oximetry.org/ pulseox/history.htm. Accessed July 11, 2015.

20. Lin JC, Strauss RG, Kulhavy JC, et al. Phlebotomy overdraw in the neonatal intensive care nursery. Pediatrics. 2000;106(2):E19.

21. Barker SJ. "Motion-resistant" pulse oximetry: a comparison of new and old models. Anesth Analg. 2002;95(4):967-972.

22. Gehring H, Hornberger C, Matz H, Konecny E, Schmucker P. The effects of motion artifact and low perfusion on the performance of a new generation of pulse oximeters in volunteers undergoing hypoxemia. Respir Care. 2002;47(1):48-60.

23. Jopling MW, Mannheimer PD, Bebout DE. Issues in the laboratory evaluation of pulse oximeter performance. Anesth Analg. 2002; 94(1 Suppl):S62-S68.

24. Shah N, Ragaswamy HB, Govindugari K, Estanol L. Performance of three new-generation pulse oximeters during motion and low perfusion in volunteers. J Clin Anesth. 2012;24(5):385-391. doi:10.1016/j. jclinane.2011.10.012.

25. Jubran A. Pulse oximetry. Crit Care. 2015;19:272. doi:10.1186/s13054015-0984-8.

26. Brown L, Dannenberg B. Pulse oximetry in discharge decision-making: a survey of emergency physicians. CJEM. 2002;4(6):388-393. 
27. Callahan JM. Pulse oximetry in emergency medicine. Emerg Med Clin North Am. 2008;26(4):869-879, vii. doi:10.1016/j.emc.2008.08.006.

28. Choi J, Claudius I. Decrease in emergency department length of stay as a result of triage pulse oximetry. Pediatr Emerg Care. 2006;22(6): 412-414.

29. Duke T, Subhi R, Peel D, Frey B. Pulse oximetry: technology to reduce child mortality in developing countries. Ann Trop Paediatr. 2009;29(3):165-175. doi:10.1179/027249309X12467994190011.

30. Kattwinkel J, Perlman JM, Aziz K, et al. Neonatal resuscitation: 2010 American Heart Association Guidelines for Cardiopulmonary Resuscitation and Emergency Cardiovascular Care. Circulation. 2010;122(18 Suppl 3):S909-S919. doi:10.1161/CIRCULATIONAHA. 110.971119

31. Altuncu E, Ozek E, Bilgen H, Topuzoglu A, Kavuncuoglu S. Percentiles of oxygen saturations in healthy term newborns in the first minutes of life. Eur J Pediatr. 2008;167(6):687-688.

32. Kamlin CO, O'Donnell CP, Davis PG, Morley CJ. Oxygen saturation in healthy infants immediately after birth. $J$ Pediatr. 2006;148(5): $585-589$.

33. Mariani G, Dik PB, Ezquer A, et al. Pre-ductal and post-ductal O2 saturation in healthy term neonates after birth. J Pediatr. 2007;150(4): 418-421.

34. Rabi Y, Yee W, Chen SY, Singhal N. Oxygen saturation trends immediately after birth. J Pediatr. 2006;148(5):590-594.

35. Amoozgar H, Ghodsi H, Borzoee M, Amirghofran AA, Ajami G, Serati Z. Detection of pulsus paradoxus by pulse oximetry in pediatric patients after cardiac surgery. Pediatr Cardiol. 2009;30(1):41-45. doi:10.1007/s00246-008-9274-4.

36. Bendjelid $\mathrm{K}$. The pulse oximetry plethysmographic curve revisited. Curr Opin Crit Care. 2008;14(3):348-353. doi:10.1097/ MCC.0b013e3282fb2dc9.

37. Lima A, Bakker J. Noninvasive monitoring of peripheral perfusion. Intensive Care Med. 2005;31(10):1316-1326.

38. Arlettaz R, Bauschatz AS, Monkhoff M, Essers B, Bauersfeld U. The contribution of pulse oximetry to the early detection of congenital heart disease in newborns. Eur J Pediatr. 2006;165:94-98.

39. Hoffman JI. It is time for routine neonatal screening by pulse oximetry. Neonatology. 2011;99(1):1-9. doi:10.1159/000311216.

40. Cunningham S, McMurray A. The availability and use of oxygen saturation monitoring in primary care in order to assess asthma severity. Prim Care Respir J. 2006;15:98-101.

41. Kline JA, Hernandez-Nino J, Newgard CD, Cowles DN, Jackson RE, Courtney DM. Use of pulse oximetry to predict in-hospital complications in normotensive patients with pulmonary embolism. Am J Med. 2003;115:203-208.

42. Kelly AM, McAlpine R, Kyle E. How accurate are pulse oximeters in patients with acute exacerbations of chronic obstructive airways disease? Respir Med. 2001;95:336-340.

43. Parameswaran GI, Brand K, Dolan J. Pulse oximetry as a potential screening tool for lower extremity arterial disease in asymptomatic patients with diabetes mellitus. Arch Intern Med. 2005;165:442-446.

44. Pope J, McBride J. Consultation with the specialist: respiratory failure in children. Pediatr Rev. 2004;25(5):160-167.

45. Petterson MT, Begnoche VL, Graybeal JM. The effect of motion on pulse oximetry and its clinical significance. Anesth Analg. 2007; 105(6 Suppl):S78-S84.
46. Kim V, Benditt JO, Wise RA, Sharafkhaneh A. Oxygen therapy in chronic obstructive pulmonary disease. Proc Am Thorac Soc. 2008; 5(4):513-518. doi:10.1513/pats.200708-124ET.

47. Gavlak JC, Stocks J, Laverty A, et al. The Young Everest Study: preliminary report of changes in sleep and cerebral blood flow velocity during slow ascent to altitude in unacclimatised children. Arch Dis Child. 2013;98(5):356-362. doi:10.1136/archdischild-2012-302512.

48. Ross PA, Newth CJL, Khemani RG. Accuracy of pulse oximetry in children. Pediatrics. 2014;133(1):22-29. doi:10.1542/peds.2013-1760.

49. National Institute for Health and Care Excellence (NICE) guidance. Bronchiolitis in children. 2015. Available from: http://www.nice.org. uk/guidance/ng9. Accessed July 19, 2015.

50. Everard ML. Respiratory syncytial virus associated lower respiratory tract disease. In: Taussig LM, Landau LI, LeSouëf PN, Martinez FD, Morgan WJ, Sly PD, editors. Pediatric Respiratory Medicine. Philadelphia, PA: Mosby-Elsevier; 2008:491-499.

51. Scottish Intercollegiate Guidelines Network. Bronchiolitis in children: a national clinical guideline. Available from: http://www.sign.ac.uk. Accessed June 7, 2015.

52. Vinci R, Bauchner H. Bronchiolitis, deception in research, and clinical decision making. JAMA. 2014;312(7):699-700. doi:10.1001/ jama.2014.8638.

53. Quinonez RA, Schroeder AR. Safely doing less and the new AAP bronchiolitis guideline. Pediatrics. 2015;135(5):793-795. doi:10.1542/ peds.2014-3703.

54. Hunt CE, Corwin MJ, Weese-Mayer DE, et al; Collaborative Home Infant Monitoring Evaluation (CHIME) Study Group. Longitudinal assessment of hemoglobin oxygen saturation in preterm and term infants in the first six months of life. J Pediatr. 2011;159(3):377-383.e1. doi:10.1016/j.jpeds.2011.02.011

55. Schondelmeyer AC, Simmons JM, Statile AM, et al. Using quality improvement to reduce continuous pulse oximetry use in children with wheezing. Pediatrics. 2015;135(4):e1044-e1051. doi:10.1542/ peds.2014-2295.

56. Lutter NO, Urankar S, Kroeber S. False alarm rates of three thirdgeneration pulse oximeters in PACU, ICU and IABP patients. Anesth Analg. 2002;94(1 Suppl):s69-s75.

57. Jones K. Alarm fatigue a top patient safety hazard. CMAJ. 2014; 186(3):178. doi:10.1503/cmaj.109-4696.

58. Keesler J. The dangers of alarm fatigue. Nurs Manage. 2014;45(4): 8,10 .

59. Ulrich B. Alarm fatigue: a growing problem. Nephrol Nurs J. 2013; 40(4):293, 346

60. Joint Commission. National patient safety goal on alarm management. Joint Commission Perspectives. 2013;33(7):1-4. Available from: http:// www.jointcommission.org/assets/1/18/JCP0713_Announce_New_ NSPG.pdf. Accessed July 20, 2015.

61. Martin S, Martin J, Seigler T. Evidence-based protocols to guide pulse oximetry and oxygen weaning in inpatient children with asthma and bronchiolitis: a pilot project. J Pediatr Nurs. 2015. doi:10.1016/j. pedn.2015.02.003.
Therapeutics and Clinical Risk Management

\section{Publish your work in this journal}

Therapeutics and Clinical Risk Management is an international, peerreviewed journal of clinical therapeutics and risk management, focusing on concise rapid reporting of clinical studies in all therapeutic areas, outcomes, safety, and programs for the effective, safe, and sustained use of medicines. This journal is indexed on PubMed Central, CAS,
Dovepress

EMBase, Scopus and the Elsevier Bibliographic databases. The manuscript management system is completely online and includes a very quick and fair peer-review system, which is all easy to use. Visit http://www.dovepress.com/testimonials.php to read real quotes from published authors. 